\title{
Understanding the relationships between ecosystem services and associated social-ecological drivers in a karst region: A case study of Guizhou Province, China
}

\section{Sijing Qiu}

Peking University, China

Jian Peng $(\mathbb{1}$

Peking University, China

Jianquan Dong

Peking University, China

\section{Xiaoyu Wang}

Peking University, China
Zihan Ding

Peking University, China

Hanbing Zhang

Peking University, China

Qi Mao

Peking University, China
Progress in Physical Geography 202I, Vol. 45(I) 98-II4

(C) The Author(s) 2020 Article reuse guidelines: sagepub.com/journals-permissions DOI: I0.II77/0309|33320933525

journals.sagepub.com/home/ppg

@SAGE
Hongyan Liu $\odot$

Peking University, China

Timothy A Quine

University of Exeter, UK

Jeroen Meersmans

University of Liège, Belgium

\begin{abstract}
Understanding the relationships among multiple ecosystem services could improve the landscape capacity to provide benefits to human society. However, the underlying mechanisms shaping ecosystem services relationships are still unclear although some studies have been conducted to explore how natural and socioeconomic factors influence the relationships among ecosystem services. In this study, the karst landscape in southwestern China, a vulnerable system with intensive human activities, was focused on, aiming to explore relationships between ecosystem services and associated social and ecological factors. The results showed that the distribution of eight individual ecosystem services were spatially heterogeneous and clustered based on the characteristics of the karst landscape. The relationships between provisioning services and regulating services, such as grain production and net primary productivity, as well as water yield and soil retention, were quite different between high karst coverage regions and low karst coverage regions. Among five ecosystem service bundles identified, ecosystem services in the urban development bundle were mainly determined by socioeconomic factors, while in the other four bundles of multifunction, grain production, habitat conservation, and carbon sequestration, ecosystem services were dominated by ecological factors. However, socioeconomic factors (i.e. population density and night-time light intensity) appeared to explain the overall ecosystem service delivery more than karst terrain. This study provided insights for sustainable ecosystem management in a vulnerable karst region through exploring social-ecological factors of the relationships among ecosystem services.
\end{abstract}

\section{Keywords}

Ecosystem service bundle, trade-offs and synergies, determinants, karst region, landscape sustainability

\section{Corresponding author:}

Jian Peng, College of Urban and Environmental Sciences and MOE Laboratory for Earth Surface Processes, Peking University, Beijing 10087I, China.

Email: jianpeng@urban.pku.edu.cn. 


\section{Introduction}

Karst is a particular type of landscape that is developed on soluble rocks, characterized by extensive underground systems and accounting for approximately $15 \%$ of global terrestrial land area (Ford and Williams, 2013). However, ecosystem degradation has occurred in some karst regions globally due to intensive human activities (Day, 2010; Jiang et al., 2014; Parise and Pascali, 2003). As the largest continuous karst region in the world, the karst region in southwestern China is such a typical ecologically vulnerable area with soil thickness usually less than $10 \mathrm{~cm}$ and a strongly developed underground cave system resulting in a lack of surface runoff (Brandt et al., 2018; Chen et al., 2011). Extensive exploitation of natural resources due to remarkable population increase has caused serious eco-environmental issues in this region including severe soil erosion, land degradation as well as increased bare rock exposure, which greatly threaten regional sustainable development (Wang et al., 2004; Zhang et al., 2017). In this context, incorporating specific karst social-ecological characteristics into ecosystem management to improve karst landscape sustainability is urgently required (Tong et al., 2018).

The concept of ecosystem services (ESs), referring to benefits that human directly or indirectly obtained from ecosystems, has been widely recognized by scientists and policy-makers as an efficient guide for sustainable ecosystem management (Costanza et al., 1997; Daily, 1997; Peng et al., 2018; Quintas-Soriano et al., 2019). Understanding how ESs interact with each other in complex and changing environments has become one main hurdle to uptake the concept into policy-making (Hölting et al., 2019; Renard et al., 2015; Saidi and Spray, 2018). Consequently, growing attention has been given to measuring ES relationships. Trade-offs, synergies, and bundles are generally applied to describe relationships among ESs (e.g. Bennett et al., 2009; Cord et al., 2017; Mouchet et al.,
2014; Raudsepp-Hearne et al., 2010), and multiple studies have been conducted in various landscapes. However, the mechanism of natural and social impacts on relationships among ESs is still unclear (Hamann et al., 2015; Peng et al., 2020; Spake et al., 2017; Zhao et al., 2018). Quantitatively analyzing relationships between ESs and their social-ecological drivers are necessary if the capacity of the karst landscape to provide more benefits to society is expected to improve over time (Turner et al., 2014).

Currently, case studies that incorporate the concept of ESs in Chinese karst regions have evaluated spatiotemporal changes of ESs (Feng et al., 2016; Zhang et al., 2011, 2015, 2018) and quantified trade-offs or synergies between pairs of ESs within the whole landscape (Lang and Song, 2018; Tian et al., 2016). However, the uniqueness of karst geological features has been less considered, and studies coupling socialecological factors to explore the driving mechanisms behind ES relationships in the context of karst landscape are also few (Wang et al., 2019). Against this background, taking the typical karst region of China, Guizhou Province, as the study area, with the perspective from individual ESs to interactions between pairs of ESs and further to associations of multiple ESs, this study aimed to assess the impact of main socialecological factors on ES relationships. Specifically, the main objectives of this study were: (a) to explore whether karst landforms could alter ES relationships in the region; and (b) to ascertain whether natural or socioeconomic factors contribute more to ES associations, that is, ES bundles.

\section{Materials and methods}

\section{Study area and data sources}

This study was carried out in Guizhou Province $\left(103^{\circ} 36^{\prime}-109^{\circ} 35^{\prime} \mathrm{E}, 24^{\circ} 37^{\prime}-29^{\circ} 13^{\prime} \mathrm{N}\right)$ with the total area of $1.76 \times 10^{5} \mathrm{~km}^{2}$, which is located in the center of southwestern China (Figure 1). The region is called "Karst Province" because 


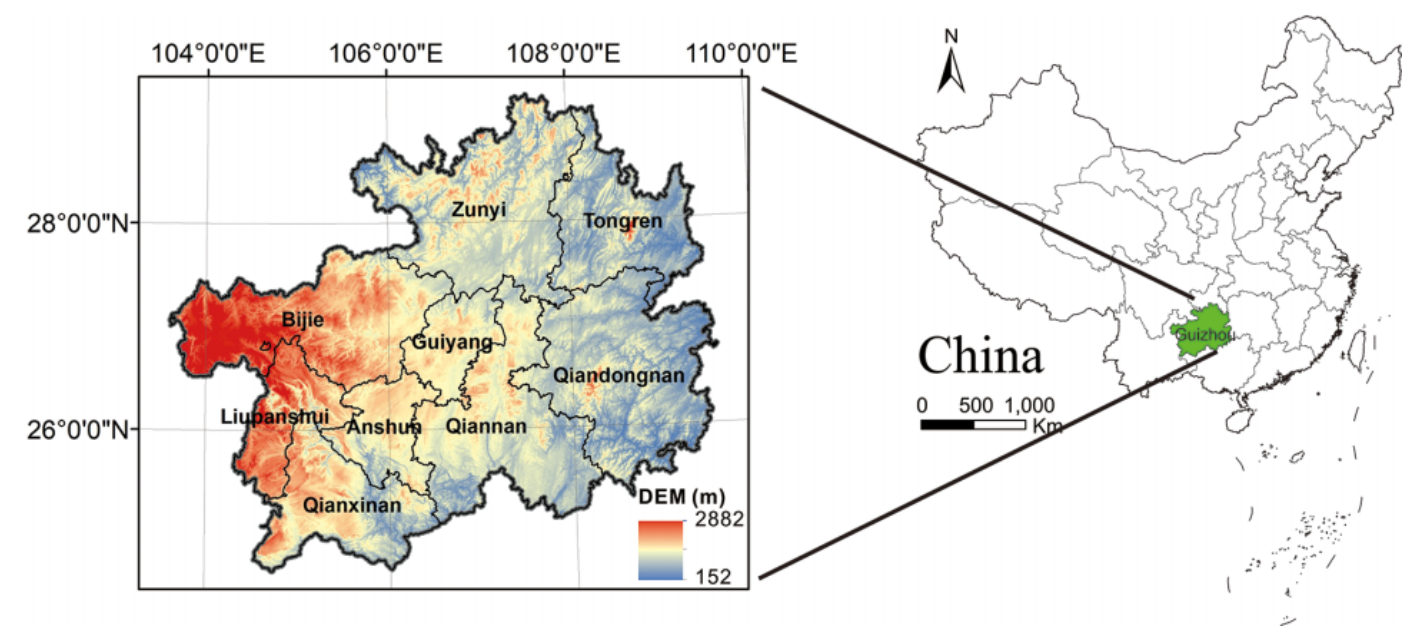

Figure I. Geographical location of the study area.

over $60 \%$ of the total area is covered by the outcrop carbonate karst. The unique geological structure results in a vulnerable ecosystem. More than $90 \%$ of the total area of Guizhou Province is occupied by mountains or hills with an average elevation of $\sim 1100 \mathrm{~m}$, characterized by high topographical complexity. Due to the subtropical humid monsoon climate, there is abundant annual precipitation, that is, 900$1300 \mathrm{~mm}$ mainly concentrated in the spring and summer, whereas the annual average temperature is $14-16^{\circ} \mathrm{C}$ (Cai et al., 2014). As a consequence of these climatological conditions, more than $50 \%$ of the region is occupied by forests with high biodiversity, especially endemic species (Clements et al., 2006). However, $80 \%$ of the cultivated land is distributed on slopes greater than $6^{\circ}$, causing severe land degradation. In 2018 , over $2.47 \times 10^{4} \mathrm{~km}^{2}$ of the region was identified as Karst Rocky Desertification Area by the National Forestry and Grassland Administration, China. There are nine municipalities in the study area (Figure 1) and the socioeconomic status is quite underdeveloped. Population pressure is very high with more than 36 million inhabitants in 2019, many of whom live in poverty in remote mountain villages.
The overall approach of this study is as follows: (a) eight ecosystem services including grain production (GP), water yield (WY), net primary productivity (NPP), soil organic carbon (SOC), soil retention (SR), habitat quality (HQ), tourism (TR), and outdoor recreation (OR) across the study area were mapped using multiple datasets and models (Table 1); (b) Spearman correlation analysis between pairs of ESs were applied respectively in regions with different coverage of karst landform to explore whether karst geological environment altered ES interactions; (c) cluster analysis was conducted to identify ecosystem service bundles at the township level based on the combination of Principal Components Analysis and the K-means Cluster method; and (d) four indicators were selected to explore social-ecological impacts on ES bundles through redundancy analysis. Data used in this study are shown in Table 1.

\section{Quantification of ESs}

Eight types of ecosystem services were considered in this study, including provisioning services, regulating services as well as cultural services which were relevant to local socialecological characteristics and associated with 
Table I. Data sources used in this study.

\begin{tabular}{|c|c|c|c|}
\hline Data type & Data use & Data format & Data source \\
\hline Land cover & $\begin{array}{l}\text { GP, WY, } \\
\text { HQ }\end{array}$ & $\begin{array}{l}\text { Digital grids at } 30 \mathrm{~m} \\
\text { resolution }\end{array}$ & $\begin{array}{l}\text { Resource and Environment Data Cloud Platform (http:// } \\
\text { www.resdc.cn) }\end{array}$ \\
\hline Soil properties & WY, SR & Shapefile & China I:I000000 Soil Datasets (http://vdb3.soil.csdb.cn/) \\
\hline Climatic factors & $\begin{array}{l}\text { WY, SR, } \\
\text { NPP }\end{array}$ & Shapefile & $\begin{array}{l}\text { China Meteorological data sharing service system (http:// } \\
\text { data.cma.cn/) }\end{array}$ \\
\hline Grain production & GP & $\begin{array}{l}\text { Statistical data at the } \\
\text { municipal level }\end{array}$ & Guizhou Yearbook (http://www.guizhou.gov.cn/zfsj/tjnj/) \\
\hline $\begin{array}{l}\text { Normalized Differential } \\
\text { Vegetation Index } \\
\text { (NDVI) }\end{array}$ & $\begin{array}{l}\text { GP, NPP, } \\
\quad \text { SR }\end{array}$ & $\begin{array}{l}\text { Digital grids at } 250 \mathrm{~m} \\
\text { resolution }\end{array}$ & $\begin{array}{l}\text { National Aeronautics and Space Administration (http:// } \\
\text { modis.gsfc.nasa.gov) }\end{array}$ \\
\hline $\begin{array}{l}\text { Digital Elevation Model } \\
\text { (DEM) }\end{array}$ & SR & $\begin{array}{l}\text { Digital grids at } 90 \mathrm{~m} \\
\text { resolution }\end{array}$ & United States Geological Survey (www.usgs.gov) \\
\hline $\begin{array}{l}\text { The fraction of green } \\
\text { vegetation cover } \\
\text { (FCover) }\end{array}$ & OR & $\begin{array}{l}\text { Digital grids at } \mathrm{I} / 3 \mathrm{~km} \\
\text { resolution }\end{array}$ & $\begin{array}{l}\text { Copernicus Global Land Service (https:// } \\
\text { land.copernicus.eu/global/products/fcover) }\end{array}$ \\
\hline Night-time light intensity & $\begin{array}{l}\text { Social } \\
\text { impact }\end{array}$ & $\begin{array}{l}\text { Digital grids at } 500 \mathrm{~m} \\
\text { resolution }\end{array}$ & $\begin{array}{l}\text { National Oceanic and Atmospheric Administration's } \\
\text { Earth Observation Group (https:// } \\
\text { www.ngdc.noaa.gov/eog/viirs.html) }\end{array}$ \\
\hline Karst distribution & $\begin{array}{l}\text { Ecological } \\
\text { impact }\end{array}$ & Shapefile & $\begin{array}{l}\text { Institute of Karst Geology in Chinese Academy of } \\
\text { Geological Sciences }\end{array}$ \\
\hline Population density & $\begin{array}{l}\text { Social } \\
\text { impact }\end{array}$ & $\begin{array}{l}\text { Digital grids at I km } \\
\text { resolution }\end{array}$ & $\begin{array}{l}\text { Resource and Environment Data Cloud Platform } \\
\text { (http://www.resdc.cn) }\end{array}$ \\
\hline
\end{tabular}

addressing local needs (Haines-Young and Potschin, 2018). The two provisioning services (Grain Production and Water Yield) and four regulating services (Soil Retention, Soil Organic Carbon, Net Primary Productivity, and Habitat Quality) were selected mainly based on the following considerations (Wang et al., 2019): (a) the barren soil and soil erosion mainly because of karst mountainous environment and agricultural activities on the slopes, revealing the importance of quantifying soil retention; (b) spatiotemporal heterogeneity of water resource due to monsoon climate and karst intensive underground water system, indicating the importance of estimating water yield; (c) insufficient food supply because of limited farmland for cultivation, unfertilized soils, and high population density, indicating the necessary assessment of food production; and (d) high natural vegetation coverage revealing the importance of biodiversity conservation and carbon sequestration, that is, calculating habitat quality, net primary productivity, and soil organic carbon. Additionally, the two cultural services of tourism and outdoor recreation were considered due to the recreational needs of residents and visitors. Pixel-based ecosystem services quantification were first applied individually and subsequently resampled to the administrative units of 1385 townships in order to better support landscape management decisions.

I Grain Production (GP). Grain production was estimated at the pixel-scale based on the linear relationship between the Vegetation Index and grain production (Peng et al., 2019a; Zhao et al., 2018). The vegetation index used in this study was annual NDVI. The grain types obtained from the statistical data for each municipality include cereals, beans and tubers. Considering the grain type grown in different types of land cover, rice production was allocated onto paddy fields, with the other types of 
grain production for dry land. The NDVI of the two types of land-use type was exacted first and then the grain production for each pixel was calculated as

$$
G_{i}=\frac{N D V I_{i}}{N D V I_{\text {sum }}} \times G_{\text {sum }}
$$

where $G_{i}$ is the grain production of grid $i, G_{\text {sum }}$ is the total grain production for each municipality. Here, $N D V I_{i}$ is the NDVI of grid $i$, and $N D V I_{\text {sum }}$ is the total NDVI for the corresponding land cover of each municipality.

2 Water yield (WY). Water yield is a measurement of water availability (Liu et al., 2016). The annual water yield for each pixel in the study area was estimated by the water balance equation

$$
Y_{x j}=\left(1-\frac{A E T_{x j}}{P_{x}}\right) \times P_{x}
$$

where $Y_{x j}$ is water yield for the grid $x$ of land-use type $j, A E T_{x j}$ is the annual actual evapotranspiration for the grid $x$ of land-use type $j, P_{x}$ is the annual precipitation for the grid $x$. Here, $\frac{A E T_{x j}}{P_{x}}$ was quantified based on the Budyko curve proposed by Fu (1981) and Zhang et al. (2004). The water yield module in the model of InVEST, that is, the Integrated Valuation of Ecosystem Services and Trade-offs, was used to quantify this service (for details, see Sharp et al., 2018).

3 Soil retention (SR). Soil erosion is a key factor in the process of land degradation and desertification, which is especially critical in karst regions where shallow soils are widely distributed across mountainous and hilly areas. Soil retention was measured using the Revised Universal Soil Loss Equation (RUSLE) (details see Appendix)

$$
A=R \times K \times L S \times(1-C \times P)
$$

where $A$ is soil retention, $R$ is rainfall erosivity factor, $K$ is soil erodibility factor, $L$ is slope length factor, $S$ is slope factor, $C$ is land cover and management factor, and $P$ is support practice factor (Feng et al., 2016; Renard et al., 1997; Williams et al., 1983).
4 Soil organic carbon (SOC). The key role of terrestrial carbon sequestration and storage is widely recognized (Pagiola, 2008). SOC is the main component of terrestrial carbon stock and an indicator for ES assessment as well (Ottoy et al., 2017; Zhao et al., 2018). The SOC in the top soil layer $(0-15 \mathrm{~cm})$ was obtained from the dataset of the World Soil Information (www.soilgrids.org), which provided a global digital map of soil properties at spatial resolution of $250 \mathrm{~m}$.

5 Net primary productivity (NPP). NPP refers to the remaining part of the organic substance amount produced by green plants with photosynthesis deducting autotrophic respiration, which indicates the forest carbon sequestration, and hence, climate regulation potential (Field et al., 1998). NPP was quantified using the Carnegie-AmesStanford Approach (CASA) model, which was widely used based on light use efficiency theory to estimate ecosystem NPP with satellite data (Potter et al. 1993). The CASA model can be described as follows

$$
N P P(x, t)=\operatorname{APAR}(x, t) \times \xi(x, t)
$$

where $A P A R(x, t)$ is the photosynthetically active radiation absorbed at the grid $x$ in the month $t$ and $\xi(x, t)$ is the actual light energy utilization at the grid $x$ in the month $t$. Here, $\operatorname{APAR}(x, t)$ is determined by the function of solar radiation and the linear relationship between the fraction of photosynthesis active radiation and reflectance properties expressed through NDVI, and $\xi(x, t)$ is estimated through temperature stress, water stress, and maximum light energy utilization. Locally specific estimation of APAR and $\xi$ was developed by Zhu et al. (2006).

6 Habitat quality (HQ). Habitat is defined as the area that provides sustainable resources and ecological conditions for the living of an organism. Habitat quality is a proxy to evaluate the ability of the ecosystem to provide conditions appropriate for individual and population 
persistence (Hall et al., 1997). In this study, habitat quality was estimated using the Habitat Quality module of InVEST model based on land cover types and local threats to biodiversity (Sharp et al., 2018). Habitat quality is determined by relative impact of threats, sensitivity of habitats to threats, distance between habitats and the threat sources and the impact of the threats across space (Sun et al., 2018). Such threat sources as agricultural cultivation, urban construction, and road traffic were considered here. The sensitivity of different threat sources for multiple land-use types was based on previous studies (Leh et al., 2013; Sharp et al., 2018).

7 Tourism (TR). Many kinds of tourism attractions, especially natural attractions, originate in ecosystem structure and process. Therefore, referencing Raudsepp-Hearne et al. (2010) and Yang et al. (2015), tourism attractions were used to quantify the potential provisioning of tourism services. According to an official list of tourism attractions published by the Cultural and Tourism Department of Guizhou Province (http://whhly.guizhou.gov.cn/wsfw/bmlqfw/ whlyggfw/lyjdjqcx/), there were 359 tourism destinations ranked into four levels of value (2A-5A; see Supplement Figure S1). These levels were used to quantify the relative value of the destinations. In order to take the spillover effects of tourism attractions (i.e. benefits provided to surrounded area) into account, Kernel Density Analysis in ArcGIS (ESRI, 2011) was applied to create a spatially continuous map of tourism value.

8 Outdoor recreation (OR). A vegetated landscape with high degree of naturalness and open structure can improve physical and mental health (Derkzen et al., 2015), therefore, more and more people showed their preference for outdoor recreational activities. The fraction of green vegetation cover (FCover) was mapped, which represented the spatial extent of vegetation and was used as a quantitative proxy for outdoor recreational opportunities in previous studies (Li et al., 2019; Raudsepp-Hearne et al., 2010). The FCover was obtained for the local growing season (April to November) (Tong et al., 2018), from PROBA-V satellite data released by Copernicus Global Land Service (https://land.copernicus.eu/global/products/fco ver). To reduce error caused by cloud and atmospheric variability, FCover of the growing season was calculated by choosing the maximum value of the datasets (Tong et al., 2016).

\section{Comparison of interactions among ES pairs}

In order to further explore how the unique karst landform impacted the interactions between pairs of ESs, the whole study area at the township scale was divided into two types (see Supplement Figure S2), that is, (a) the towns with karst landform coverage more than the average level of the study area (high karst coverage region; HKCR), and (b) all the other towns (low karst coverage region; LKCR). Because correlation analysis has been widely used to examine ecosystem service interactions (Hölting et al., 2019), Spearman correlation analysis between pairs of ESs was performed across the entire region (ER), HKCR, and LKCR, in order to explore whether the presence of karst landforms altered ES interactions.

\section{Identification of ES bundles}

Two steps were adopted for identifying ES bundles. Principal Components Analysis (PCA) was used to explore the co-occurrence of ESs. K-means clustering was then applied to the PCA axes scores. The appropriate number of clusters was determined by scree plots, which found the cluster solution with the lowest within-cluster sum of squares. The number of iterations of $\mathrm{K}$-means was set as 1000 to get stable cluster results using the Hartigan-Wong algorithm 
(Hartigan and Wong, 1979; Renard et al., 2015; Turner et al., 2014).

\section{Determination of ES bundle drivers}

To explore how natural and socioeconomic factors impacted ES delivery, and hence, to find the determining factors for each ES bundle, four main explainable variables were selected for redundancy analysis (RDA). RDA is a common method for exploring the relationship between multivariate response variables and several explanatory variables (Legendre, 2012; Zoderer et al., 2019). Based on the characteristics of the mountainous karst region, mean elevation and the proportion of karst landform coverage (Karst.rate) of each township were chosen as the natural variables to represent the uniqueness as regards topography and landform. The socioeconomic variables of population density and night-time light (NTL) intensity, widely applied in estimating socioeconomic activities, were included (Elvidge et al., 2017; Ma et al., 2014).

In order to identify the significant predictors of ES bundles, a multinomial logit model was applied based on the results of cluster analysis. In the multinomial logit model, the log-odds (the log of the odds ratio) of a town in the reference category changing its belonging to another category (i.e. the other four bundles) was set as a function of social-ecological predictors. This could provide insights into how to improve ESs provisioning, and could further inform ecosystem management policy-making.

To make different variables comparable, social-ecological variables and ES indicators were transformed to be dimensionless using z-score standardization. ES spatial distributions were mapped in ArcGIS 10.4 and analyzed using the Moran's I with Queen contiguity to determine spatial autocorrelation characteristics (Raudsepp-Hearne et al., 2010). Spearman correlation analysis, PCA, K-means, and RDA were all performed in $\mathrm{R}$ software v.3.6.2 (R Core Team, 2019).

\section{Results}

\section{ES spatial distribution}

Figure 2 shows that all ESs were significantly spatially clustered within the study area (Moran's $I>0.62, p<0.001$ ). Spatial patterns of different types of ES were highly heterogeneously distributed as a consequence of the variety in social-ecological features of the karst landscape. For provisioning services, high grain production was mainly in the regions characterized by large areas of paddy field or dry land. Water yield was highest on artificial land and also concentrated in the southeast of the study area with low mountains and hills but high annual precipitation. When considering regulating services, NPP and SOC presented similar spatial patterns, with mountainous areas characterized by high coverage of vegetation for hotspots. Furthermore, spatial distribution of soil retention and habitat quality were also similar with a lower value in the regions characterized by high human disturbances such as urban construction or intensive agricultural cultivation. As regards cultural services, tourism was mainly concentrated in the central area, whereas the outdoor recreation opportunities were relatively high across the whole study area except in the urban agglomeration area and in the western part of the karst plateau.

\section{Interactions among ES pairs}

Among 28 pairs of ESs, there were 25 significant correlations in ER (i.e. 12 positive and 13 negative, $p<0.01$ ), 23 in LKCR (i.e. 12 positive and 11 negative, $p<0.01$ ), and 27 in HKCR (i.e. 13 positive and 14 negative, $p<$ 0.01 ), with a little higher correlation coefficient in the latter, indicating stronger interactions between ESs in HKCR than those in LKCR (Figure 3). Overall, interactions between pairs 

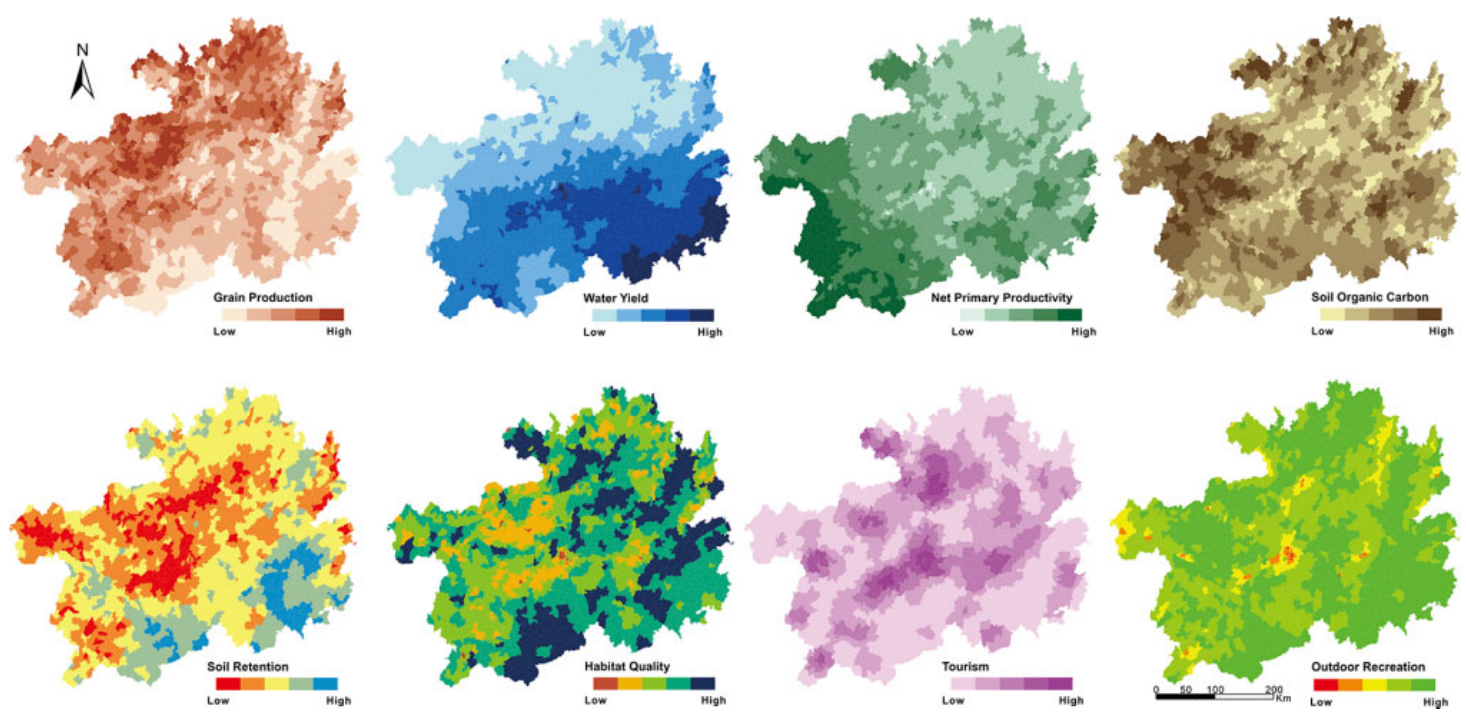

Figure 2. Spatial distribution of ecosystem services in Guizhou Province, China.

of regulating services and cultural services showed similar relationships in the three different groups (i.e. HKCR, LKCR, and ER), and significant differences mainly existed between two provisioning services and regulating services as well as cultural services. Furthermore, it was noticeable for weak correlations between grain production and NPP in ER $(r=0.053, p<$ $0.05)$ and in LKCR $(r=-0.042, p>0.05)$, but much stronger and significantly positive relationship in $\operatorname{HKCR}(r=0.14, p<0.001)$. Similar relationships were found between grain production and outdoor recreation with significant positive correlations in HKCR $(r=0.39, p<0.001)$ and in ER $(r=0.22, p<0.001)$, but with no significant correlation in LKCR $(r=-0.01$, $p>0.05)$. The negative relationships between grain production and soil retention or habitat quality in HKCR $(r=-0.11, p<0.001 ; r=$ $0.20, p<0.001)$ were weaker than those in LKCR $(r=-0.38 /-0.49, p<0.001)$. Another contrasting result across regions existed in the correlation between water yield and soil retention, which showed weak positive relationships in $\operatorname{ER}(r=0.048, p<0.05)$ and $\operatorname{LKCR}(r=0.24$, $p<0.001)$ but a significant negative relationship in HKCR $(r=-0.20, p<0.001)$.

\section{Spatial pattern of ES bundles}

The cumulative explanatory power of the first four PCA axes was $83.61 \%$, which was sufficient to characterize the eight ESs. Then based on the four PCA axes, five clusters were determined with the lowest within-cluster sum of squares using K-means method for the 1385 townships. Hence, five ES bundles were clustered and spatially identified, that is, multifunction, grain production, urban development, habitat conservation, and carbon sequestration (Figure 4). The distribution of ES bundles showed overall spatial clustering, especially for the bundles of multifunction, habitat conservation, and carbon sequestration. The multifunction bundle was composed of 315 towns far from major cities where all regulating services were relatively high but with lower agricultural provisioning and less tourism resources. The grain production bundle had 274 towns characterized by high supply of grain but the lowest quality of habitat. Only 76 towns were 

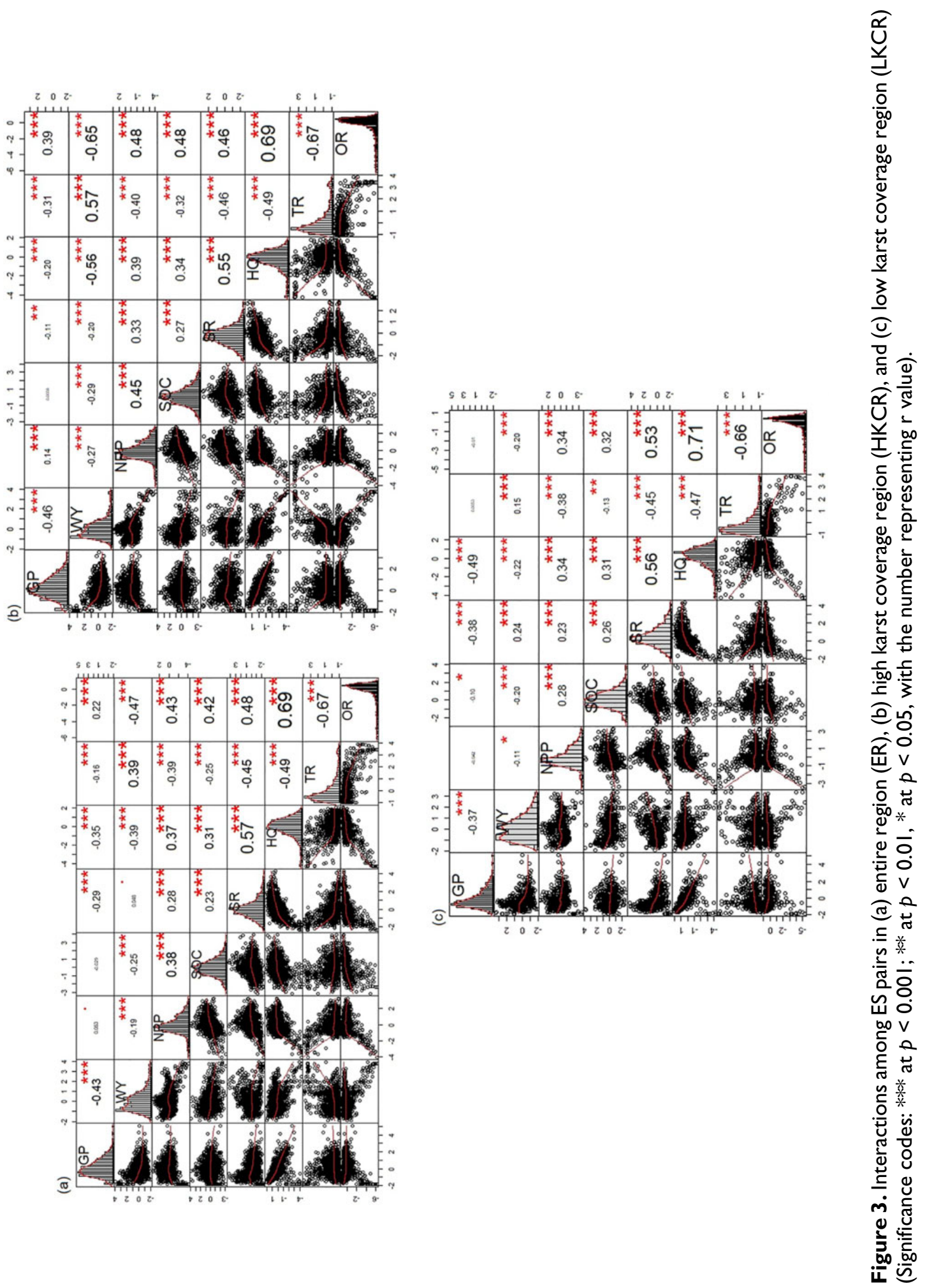

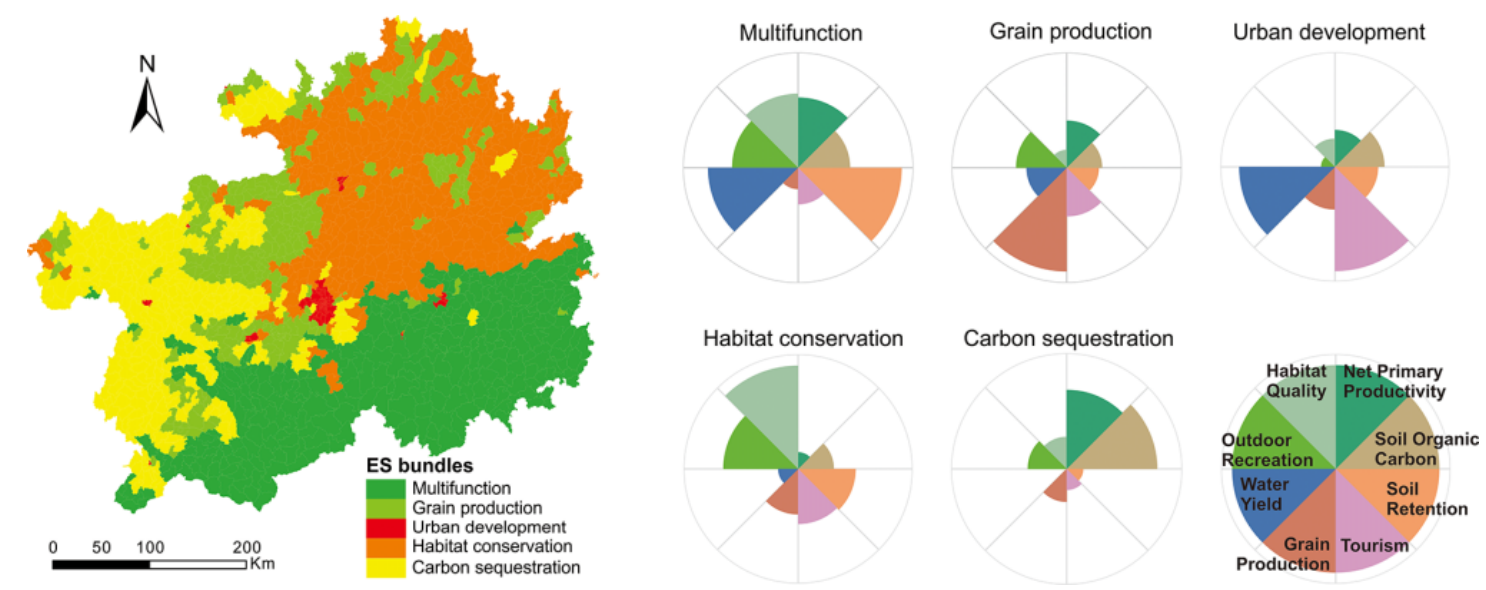

Figure 4. Spatial distribution and characteristics of ES bundles in Guizhou Province, China.

identified as the urban development bundle, which was consistent with the generally recognized underdeveloped socioeconomic status of this province. As to habitat conservation bundle, 430 towns were characterized by a high level of vegetation coverage and low degree of human disturbance. Finally, the carbon sequestration bundle covered 290 towns that were mainly located in the mountainous area and characterized by a high ability to sequester carbon due to their soil and vegetation types.

\section{Determinants of ES bundles}

The RDA indicated statistically significant association between ES indicators and explanatory variables with $R^{2}=0.39(p<0.001)$. The first axis of the RDA (explaining $71.44 \%$ of the variance) was mainly determined by socioeconomic indicators, while the second axis (explaining $20.48 \%$ of the variance) was dominated by natural indicators. The overall impacts of anthropogenic activities on ES provisioning were higher than the geological impacts in spite of specific landform and topographical settings in the karst landscape (Figure 5).

By comparing the explanatory variable axes and the town clusters of ES bundles, the determinants of each ES bundle could be identified.

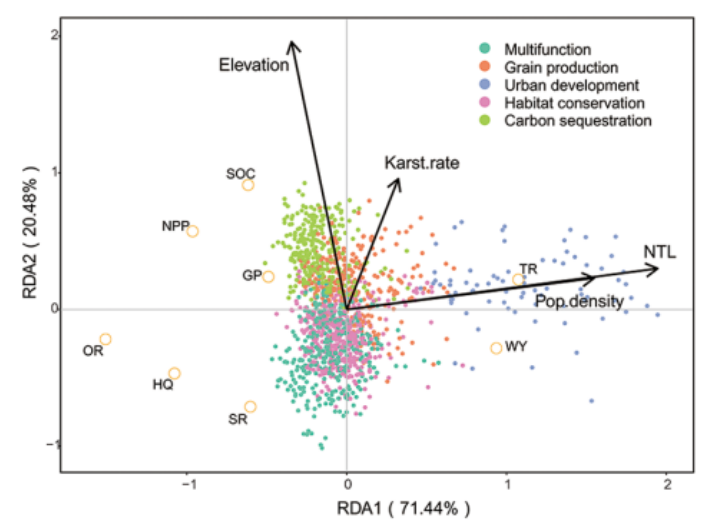

Figure 5. Redundancy analysis between ES and social-ecological explanatory variables.

The towns of the urban development bundle were positively related with socioeconomic variable axes. In contrast, most towns of the other ES bundles were distributed along the second RDA axis. This indicated that except urban development bundle, the other four bundles were more determined by the natural drivers. Moreover, the towns of the carbon sequestration bundle were mainly positively related with the Elevation and Karst.rate axes, revealing positive relationships between the two natural variables and ES provisioning. Most of the towns belonging to the habitat 
Table 2. Estimated model coefficients for category change of ES bundles in response to social-ecological factors.

ES bundles transformation

\begin{tabular}{lcccc}
\cline { 2 - 5 } $\begin{array}{l}\text { Social-ecological } \\
\text { predictors }\end{array}$ & $\begin{array}{c}\text { Multifunction -> } \\
\text { Grain production }\end{array}$ & $\begin{array}{c}\text { Multifunction }-> \\
\text { Urban development }\end{array}$ & $\begin{array}{c}\text { Multifunction }-> \\
\text { Habitat conservation }\end{array}$ & $\begin{array}{c}\text { Multifunction -> } \\
\text { Carbon sequestration }\end{array}$ \\
\hline Karst landform proportion & $0.632^{* *}$ & 0.460 & $0.745^{* *}$ & 0.236 \\
Elevation & $-0.059^{* *}$ & -0.351 & -1.013 & $2.277^{* *}$ \\
Night-time light intensity & 0.682 & $2.753^{*}$ & -0.359 & -0.542 \\
Population density & $33.197^{* *}$ & $41.039 * *$ & $31.208^{* *}$ & $30.804^{* *}$ \\
\hline
\end{tabular}

Significance denoted by $* *$ at $p<0.001$, * at $p<0.01$.

conservation bundle and multifunction bundle were located in regions characterized by small areas of karst landforms and with lower population density and human disturbance as indicated by the lower value of NTL intensity. However, for the grain production bundle, the towns were scattered on the explanatory variable axes, indicating that the relationships between these towns and the social and ecological variables were complex and without distinct positive or negative correlations.

For the ESs, the strong positive relationships between the two socioeconomic drivers and the services of tourism and water yield demonstrated that densely populated areas with intensive urban construction could result in high provisioning of water yield and high density of tourism attractions. However, population density and intensive human activities had negative effects for the other ESs. Also, high coverage of karst landforms and high elevation had negative impacts on habitat quality and soil retention. Grain production was slightly influenced by these two drivers, with NPP and SOC having strong positive correlation instead. All the results indicated that ES bundles were primarily determined by landforms and topography, while such social variables as population density and night-time light intensity further influenced the delivery of all ecosystem services.

The predictor of population density greatly dominated the transformations of the multifunction bundle to all the other ES bundles in the multinomial logit model, that is, more population created more potential for transformation to the other ES bundles (Table 2). Besides population density, for the transformation from multifunction bundle to grain production bundle, elevation and karst landform were also significant predictors. As to the transformation to urban development bundle, NTL intensity also became a significantly positive predictor with nonsignificance for both ecological predictors, revealing that the driving forces of this bundle were mainly intensive human activities. In terms of the predictors that distinguish the multifunction bundle from the habitat conservation and carbon sequestration bundles, low karst landform coverage in the first instance and less topographic complexity in the second were revealed in the significant positive predictors of karst landform and elevation, respectively.

\section{Discussion}

\section{Karst landform impact on ES interactions}

Previous studies found the trade-offs between provisioning and regulating as well as cultural services in different types of landscapes (Lee and Lautenbach, 2016; Raudsepp-Hearne et al., 2010; Wang et al., 2017). However, through comparing trade-offs and synergies between pairs of ESs in regions with different coverage karst landforms, it could be found that the relationships between provisioning services and other two services were not always fixed for the 
karst landscape. The special geological features of karst landscapes alter the trade-off or synergic relationships between ESs.

In HKCR there was a synergic relationship between grain production and NPP $(r=0.14$, $p<0.001)$ in contrast to nonsignificant interactions in LKCR, and similar difference also existed between grain production and outdoor recreation ( $r=0.39, p<0.001$ in HKCR). In HKCR, vegetation coverage might be largely contributed by grain crops. Residents located in this karst plateau area usually struggled to meet their basic food demand, and they had to cultivate scattered sloping farmlands of this vulnerable landscape, leading to the large distributions of cropland, but this reduced natural vegetation and thus the supply of regulating services (Liao et al., 2018). The intensive cultivation could not be considered to be sustainable, because some towns in HKCR were characterized by low levels of grain production and regulating services (Figure $3 b$ ). In addition, the trade-offs between grain production and soil retention, as well as habitat quality, were weaker in HKCR than in LKCR, which implied that when launching the ecological engineering projects in the karst region (such as Grain for Green Project, returning the slope cropland into natural vegetation), recovery of the regulating services in a high karst coverage area might not be apparent in comparison with a low karst coverage area.

Another significant change occurred for the relationship between water yield and soil retention. A former study conducted in the karst watershed found trade-offs between water yield and soil retention (Tian et al., 2016). However, in this study, the relationship between soil retention and water yield altered with the degree of karst landform coverage, that is, synergy in LKCR $(r=0.24, p<0.001)$ and trade-off in $\operatorname{HKCR}(r=-0.20, p<0.001)$. This was probably because LKCR was characterized by high precipitation, which would lead to high water yield, and also facilitate vegetation growth and thus enhance soil retention. However, in HKCR, water yield would lead to soil erosion at both the surface and underground due to the unique "dual structure" of the karst system, implying higher water yield accompanied with lower soil retention (Feng et al., 2016; Gunn, 2013). Relationships among ESs differed between the high and low karst coverage regions, and so geological factors should be given more attention in the science and management of ecosystem services.

\section{Improving the sustainability of ES provisioning}

The conservation of ecosystem functions and biodiversity are critical for maintaining the sustainability of karst landscapes. Multiple ecological engineering projects have been launched in Guizhou Province since the 1990s, aimed at restoring the degraded ecosystems (Brandt et al., 2018; Bryan et al., 2018; Zhang et al., 2017). Although a human-induced greening trend has been reported through various earth observations (Cai et al., 2014; Tong et al., 2018, 2020), the success of ecological conservation projects should not only focus on greening of surface coverage, but also emphasize the social context, in order to undertake actions which can both promote ecological sustainability and meet region-specific social demands (Peng et al., 2019b; Wang et al., 2019). Based on the characteristics of the karst landscape, five types of ES bundles were determined, which represented an emergent pattern of towns with similar sets of ecosystem services. The delivery of ESs in the multifunction bundle was more balanced and abundant except for low provision of tourism and grain production (Figure 4), but because population density was the common predictor in all the transformations, which was consistent with the RDA results, when implementing ecological conservation or restoration projects, population density-related policies should be highly focused as necessary auxiliary actions. 
The results of the ES bundles revealed that the majority of Guizhou Province was identified with a relatively high provisioning of regulating services, highlighting the importance to enhance ecosystem sustainability in the vulnerable karst landscape. The basic rule is that human activities including urban construction and agricultural cultivation should be carefully planned under strict governance in the whole study area. Given the study area is located on the upper reaches of Yangtze River and Pearl River (the longest river and the fourth longest river in China respectively), its ecosystem degradation would result in negative impacts on the welfare of downstream areas as well. Targeted policies addressing the sustainability challenges faced in different areas could also be inferred according to the determinant characteristics of each bundle. For instance, for the towns in the carbon sequestration bundle, which was mainly located on the karst plateau, the service of carbon sequestration could be maintained by conserving forest and grassland ecosystem, contributing to the increasing of soil retention and habitat quality. Meanwhile, for this densely populated area, rural labor should be further encouraged to seek job opportunities other than exploiting the sloping farmland. The area of habitat conservation bundle with high forest coverage was rich in nationally and internationally protected plants and animals. Therefore, outdoor viewing projects could be properly developed to enhance local economy based on the premise of biodiversity conservation. As to urban development bundle, the high level of water yield caused by artificial surface should be noticed in urban planning with regard to flood disasters in the humid season. Covering limited area, eco-agriculture strategies to raise yield should be explored in the grain production bundle. The main development strategy for multifunction bundles, located in low elevation and nonkarst areas, was to protect ecosystems from degradation.

\section{Limitations and future research directions}

Focusing on karst landform, this study clarified the different relationships among ecosystem services between high and low karst coverage regions, and illustrated the impacts of karst landform on ecosystem service bundles. However, some limitations persist. First, although typical ecosystem services were quantified as well as possible, some uncertainty is related to the proxies and models. For example, there were only municipal level data for grain yield in the official yearbook, which restricted the accuracy of downscaling the grain production into grid level. While NDVI was one of the most commonly used vegetation indexes, others are worth exploration in future studies. For water yield quantification, hydrological process in the study area was quite complex, as induced by underlying geology and the underground water system, and thus difficult to capture in the model. Moreover, the biodiversity protection module in the InVEST model assumed that all threats were additive, ignoring that collective impact of multiple threats was much greater than the sum of their individual threats (Sharp et al., 2018; Sun et al., 2018).

Second, using the mean value as the threshold to distinguish the high and low karst coverage regions could also be viewed as a limitation. It would be more indicative if a flexible approach could be developed to explore at finer scale how karst landform would influence the relationships between pairs of ESs. Third, population density and night-time light intensity showed the similar distribution at the town level. In view of the fact that there are some villages in the remote mountainous area with dense population but at low-level socioeconomic development for the study area, the two indicators originally selected to characterize the different dimensions of socioeconomic development were necessary.Further studies could emphasize more social-ecological variables to characterize high heterogeneity of karst 
landscape and thus to improve the understanding of ESs interactions and associated driving mechanism.

\section{Conclusion}

A deep understanding of the multiple interactions among ESs is crucial to ecosystem related policy-making. This study explored how main social-ecological factors influenced ESs delivery and their relationships in the context of karst landscape. The results showed that the relationships between provisioning services (i.e. grain production/water yield) and regulating services (i.e. NPP/soil retention) were different in high and low karst coverage regions, identifying the sensitive pairs of ESs to karst terrain. In the five ES bundles, the urban development bundle was dominated by population density and night-time light intensity, with ecological factors for the other four ES bundles. Rather than karst terrain, human activities explained more of the overall ES delivery across the study area, revealing the profound human impact on the nature, but ecological factors related to karst terrain were important in the processes of natural conservation and social development in this vulnerable karst region.

\section{Declaration of conflicting interests}

The author(s) declared no potential conflicts of interest with respect to the research, authorship, and/or publication of this article.

\section{Funding}

The author(s) disclosed receipt of the following financial support for the research, authorship, and/or publication of this article: This work was jointly financed by the National Natural Science Foundation of China (Grant No. 41571130044) and the Natural Environmental Research Council of the UK and the Newton Foundation (Grant No. NE/N007603/1, NE/S009175/ 1 and NE/S009116/1.

\section{ORCID iDs}

Jian Peng (D) https://orcid.org/0000-0003-0332-0248
Hongyan Liu (D) https://orcid.org/0000-0002-67214439

\section{Supplemental material}

Supplemental material for this article is available online.

\section{References}

Bennett EM, Peterson GD and Gordon LJ (2009) Understanding relationships among multiple ecosystem services. Ecological Letters 12(12): 1394-1404.

Brandt M, Yue YM, Wigneron JP, et al. (2018) Satelliteobserved major greening and biomass increase in South China karst during recent decade. Earth's Future 6(7): 1017-1028.

Bryan BA, Gao L, Ye YQ, et al. (2018) China's response to a national land-system sustainability emergency. Nature 559(7713): 193-204.

Cai HY, Yang XH, Wang KJ, et al. (2014) Is forest restoration in the Southwest China karst promoted mainly by climate change or human-induced factors? Remote Sensing 6(10): 9895-9910.

Chen HS, Liu JW, Wang KL, et al. (2011) Spatial distribution of rock fragments on steep hillslopes in karst region of northwest Guangxi, China. Catena 84(1-2): 21-28.

Clements R, Sodhi NS, Schilthuizen M, et al. (2006) Limestone karsts of southeast Asia: Imperiled arks of biodiversity. Bioscience 56(9): 733-742.

Cord AF, Bartkowski B, Beckmann M, et al. (2017) Towards systematic analyses of ecosystem service trade-offs and synergies: Main concepts, methods and the road ahead. Ecosystem Services 28: 264-272.

Costanza R, d'Arge R, deGroot, et al. (1997) The value of the world's ecosystem services and natural capital. Nature 387: 253-260.

Daily G (1997) Nature's Services: Societal Dependence on Natural Ecosystems. Washington, DC: Island Press.

Day M. (2010) Challenges to sustainability in the Caribbean karst. Geologia Croatica 63(2): 149-154.

Derkzen ML, van Teeffelen AJA, Verburg PH, et al. (2015) REVIEW: Quantifying urban ecosystem services based on high-resolution data of urban green space: An assessment for Rotterdam, the Netherlands. Journal of Applied Ecology 52(4): 1020-1032.

Elvidge CD, Baugh K, Zhizhin M, et al. (2017) VIIRS night-time lights. International Journal of Remote Sensing 38(21): 5860-5879. 
ESRI (2011) ArcGIS Desktop: Release 10 Environmental Systems Research Institute, Redlands, California, USA

Feng T, Chen HS, Polyakov VO, et al. (2016) Soil erosion rates in two karst peak-cluster depression basins of northwest Guangxi, China: Comparison of the RUSLE model with $137 \mathrm{Cs}$ measurements. Geomorphology 253: 217-224.

Field CB, Behrenfeld MJ, Randerson JT, et al. (1998) Primary production of the biosphere: Integrating terrestrial and Oceanic Components. Science 281(5374): 237-240.

Ford D and Williams P (2013) Karst Hydrogeology and Geomorphology. New York: Wiley.

Fu BP (1981) On the calculation of the evaporation from land surface. Scientia Atmospherica Sinica 5(1): 23-31. (in Chinese with English abstract)

Gunn J (2013) Denudation and erosion rates in karst. In: Shroder J and Frumkin A (eds) Treatise on Geomorphology. San Diego, California: Academic Press, 72-81.

Haines-Young R and Potschin M (2018) Common International Classification of Ecosystem Services (CICES) for Integrated Environmental and Economic Accounting (V5.1). Available at: https://cices.eu/resources/.

Hall LS, Krausman PR and Morrison ML (1997) The habitat concept and a plea for standard terminology. Wildlife Society Bulletin 25(1): 173-182.

Hamann M, Biggs R and Reyers B (2015) Mapping socialecological systems: Identifying 'green-loop' and 'redloop' dynamics based on characteristic bundles of ecosystem service use. Global Environmental Change 34: 218-226.

Hartigan JA and Wong MA (1979) A K-means clustering algorithm. Journal of the Royal Statistical Society. Series C (Applied Statistics) 28(1): 100-108.

Hölting L, Beckmann M, Volk M, et al. (2019) Multifunctionality assessments - More than assessing multiple ecosystem functions and services? A quantitative literature review. Ecological Indicators 103: 226-235.

Jiang ZC, Lian YQ and Qin XQ (2014) Rocky desertification in Southwest China: Impacts, causes, and restoration. Earth-Science Reviews 132: 1-12.

Lang YQ and Song W (2018) Trade-off analysis of ecosystem services in a mountainous karst area, China. Water 10(3): 300.

Lee $\mathrm{H}$ and Lautenbach S (2016) A quantitative review of relationships between ecosystem services. Ecological Indicators 66: 340-351.
Legendre P. (2012) Numerical Ecology, 3rd English edition. Amsterdam: Elsevier Science BV.

Leh MDK, Matlock MD, Cummings EC, et al. (2013) Quantifying and mapping multiple ecosystem services change in West Africa. Agriculture, Ecosystems \& Environment 165: 6-18.

Li T, Lü YH, Fu BJ, et al. (2019) Bundling ecosystem services for detecting their interactions driven by large-scale vegetation restoration: Enhanced services while depressed synergies. Ecological Indicators 99: 332-342.

Liao CJ, Yue YM, Wang KL, et al. (2018) Ecological restoration enhances ecosystem health in the karst regions of southwest China. Ecological Indicators 90: 416-425.

Liu YB, Xiao JF, Ju WM, et al. (2016) Recent trends in vegetation greenness in China significantly altered annual evapotranspiration and water yield. Environmental Research Letters 11(9): 094010.

Ma T, Zhou CH, Pei T, et al. (2014) Responses of SuomiNPP VIIRS-derived nighttime lights to socioeconomic activity in China's cities. Remote Sensing Letters 5(2): 165-174.

Mouchet M, Lamarque P, Martín-López B, et al. (2014) An interdisciplinary methodological guide for quantifying associations between ecosystem services. Global Environmental Change 28: 298-308.

Ottoy S, Meerbeek KV, Sindayihebura A, et al. (2017) Assessing top- and subsoil organic carbon stocks of Low-Input High-Diversity systems using soil and vegetation characteristics. Science of the Total Environment 589: 153-164.

Pagiola S. (2008) Payments for environmental services in Costa Rica. Ecological Economics 65(4): 712-724.

Parise M and Pascali V. (2003) Surface and subsurface environmental degradation in the karst of Apulia (southern Italy). Environmental Geology 44(3): 247-256.

Peng J, Hu XX, Qiu SJ, et al. (2019a) Multifunctional landscapes identification and associated development zoning in mountainous area. Science of the Total Environment 660: 765-775.

Peng J, Hu XX, Wang XY, et al. (2019b) Simulating the impact of Grain-for-Green Programme on ecosystem services trade-offs in Northwestern Yunnan, China. Ecosystem Services 39: 100998.

Peng J, Hu YN, Dong JQ, et al. (2020) Linking spatial differentiation with sustainability management: Academic contributions and research directions of physical 
geography in China. Progress in Physical Geography 44(1): 14-30.

Peng J, Yang Y, Liu YX, et al. (2018) Linking ecosystem services and circuit theory to identify ecological security patterns. Science of the Total Environment 644: 781-790.

Potter C, Randerson J, Field C, et al. (1993) Terrestrial ecosystem production: A process model based on global satellite and surface data. Global Biogeochemical Cycles 7(4): 811-841.

Quintas-Soriano C, García-Llorente M, Norström A, et al. (2019) Integrating supply and demand in ecosystem service bundles characterization across Mediterranean transformed landscapes. Landscape Ecology 34(7): 1619-1633.

R Core Team (2019) R: a language and environment for statistical computing. R Foundation for Statistical Computing. Vienna, Austria. https://cran.r-project.org/ doc/manuals/fullrefman.pdf

Raudsepp-Hearne C, Peterson GD and Bennett EM (2010) Ecosystem service bundles for analyzing tradeoffs in diverse landscapes. Proceedings of the National Academy of Sciences of the United States of America 107(11): 5242-5247.

Renard KG, Foster GR and Weesies GA (1997) Predicting Soil Erosion By Water: A Guide to Conservation Planning with the Revised Universal Soil Loss Equation (RUSLE). United States Department of Agriculture, Agriculture Handbook Number 703.

Renard D, Rhemtulla JM and Bennett EM (2015) Historical dynamics in ecosystem service bundles. Proceedings of the National Academy of Sciences of the United States of America 112(43): 13411-13416.

Saidi N and Spray C (2018) Ecosystem services bundles: Challenges and opportunities for implementation and further research. Environmental Research Letters 13(11): 113001.

Sharp R, Tallis HT, Ricketts T, et al. (2018) InVEST 3.7.0 User's Guide. The Natural Capital Project, Stanford University, University of Minnesota, The Nature Conservancy, and World Wildlife Fund.

Spake R, Lasseur R, Crouzat E, et al. (2017) Unpacking ecosystem service bundles: Towards predictive mapping of synergies and trade-offs between ecosystem services. Global Environmental Change 47: 37-50.

Sun X, Crittenden JC, Li F, et al. (2018) Urban expansion simulation and the spatio-temporal changes of ecosystem services: A case study in Atlanta Metropolitan area, USA. Science of the Total Environment 622-623: 974-987.
Tian YC, Wang SJ, Bai XY, et al. (2016) Trade-offs among ecosystem services in a typical Karst watershed, SW China. Science of the Total Environment 566-567: 1297-1308.

Tong XW, Brandt M, Yue YM, et al. (2018) Increased vegetation growth and carbon stock in China karst via ecological engineering. Nature Sustainability 1(1): 44-50.

Tong XW, Brandt M, Yue YM, et al. (2020) Forest management in southern China generates short term extensive carbon sequestration. Nature Communications 11(1): 129.

Tong XW, Wang KL, Brandt M, et al. (2016) Assessing future vegetation trends and restoration prospects in the karst regions of southwest China. Remote Sensing 8(5): 357.

Turner KG, Odgaard MV, Bocher PK, et al. (2014) Bundling ecosystem services in Denmark: Trade-offs and synergies in a cultural landscape. Landscape and Urban Planning 125: 89-104.

Wang JT, Peng J, Zhao MY, et al. (2017) Significant tradeoff for the impact of Grain-for-Green Programme on ecosystem services in North-western Yunnan, China. Science of the Total Environment 574: 57-64.

Wang K, Zhang C, Chen H, et al. (2019) Karst landscapes of China: Patterns, ecosystem processes and services. Landscape Ecology 34(12): 2743-2763.

Wang SJ, Liu QM and Zhang DF (2004) Karst rocky desertification in southwestern China: Geomorphology, landuse, impact and rehabilitation. Land Degradation \& Development 15(2): 115-121.

Williams JR, Renard KG and Dyke PT (1983) EPIC: A new method for assessing erosion's effect on soil productivity. Journal of Soil and Water Conservation 38(5): 381-383.

Yang GF, Ge Y, Xue H, et al. (2015) Using ecosystem service bundles to detect trade-offs and synergies across urban-rural complexes. Landscape and Urban Planning 136: 110-121.

Zhang CH, Qi XK, Wang KL, et al. (2017) The application of geospatial techniques in monitoring karst vegetation recovery in southwest China. Progress in Physical Geography 41(4): 450-477.

Zhang L, Hickel K, Dawes WR, et al. (2004) A rational function approach for estimating mean annual evapotranspiration. Water Resources Research. 40 (2): W02502.

Zhang MY, Wang KL, Liu HY, et al. (2015) How ecological restoration alters ecosystem services: An analysis of vegetation carbon sequestration in the karst area of 
northwest Guangxi, China. Environmental Earth Sciences 74(6): 5307-5317.

Zhang MY, Wang KL and Liu HY (2018) Effect of ecological engineering projects on ecosystem services in a karst region: A case study of northwest Guangxi, China. Journal of Cleaner Production 183: 831-842.

Zhang MY, Zhang CH, Wang KL, et al. (2011) Spatiotemporal variation of karst ecosystem service values and its correlation with environmental factors in northwest Guangxi, China. Environmental Management 48(5): 933-944.
Zhao MY, Peng J, Liu YX, et al. (2018) Mapping watershedlevel ecosystem service bundles in the Pearl River Delta, China. Ecological Economics 152: 106-117.

Zhu WQ, Pan YZ, He H, et al. (2006) Simulation of maximum light use efficiency for some typical vegetation types in China. Chinese Science Bulletin, 51(4): 457-463.

Zoderer BM, Tasser E, Carver S, et al. (2019) Stakeholder perspectives on ecosystem service supply and ecosystem service demand bundles. Ecosystem Services 37: 100938. 